\title{
Human Rights Organizations in Transition Countries
}

\author{
Elie Abouaoun \\ St. Joseph University
}

\begin{abstract}
The paper examines the challenges faced by the human rights organizations in the Arab region. It will focus on those challenges resulting from the radical changes that happened since 2011. It will also look into the prospective role of the human rights organizations in the future phases of the political transition.
\end{abstract}

Keywords: civil society, Arab Region, human rights organizations, countries in transition

\section{Introduction}

The prevailing public perception in the Arab region is that the government is responsible for the protection and promotion of respecting human rights. The role of other segments of the society is often questioned.

In the last two decades, there has been a growing interest in the Arab region in human rights. This interest is materialized, amongst other things, with the emergence of voluntary initiatives aiming at the promotion and respect of human rights. Many of these initiatives are now well-established Civil Society Organizations (CSO) which are able to attract large funding.

In this regard, the question that has yet to be addressed is whether all CSO in the region operate in the arena of voluntary collective actions around shared interests, purposes, and values. Can human rights actors within the Civil Society Ecosystem genuinely claim representing a well-defined constituency?

\section{The Changes}

Although it was difficult to generalize, the pre-2011 political landscape in the Arab region consisted mainly of authoritarian regimes with a set of diverse civil actors such as political opponents, intellectuals, rights groups/activists, unions, women, students, and disaffected former members of the regime. These groups were largely against the dictator in one way or another, but for various and often diverging reasons. Among these opposition groups were highly organized Islamist movements, led or inspired by the teachings of radical political Islam, excluded through brutal oppression. The extent to which all of these actors with diverse agendas evolved to become a heterogeneous, but harmonized, civil society sector (CSS) was still up for debate.

This reality severely affected the credibility and legitimacy of the CSS in the region. Prior to 2011, the CSS acted in a hostile political and legislative environment, under governments that acted persistently to challenge both their credibility and legitimacy. In countries undergoing political transition, we have seen a chaotic growth of CSS actors after 2011 that are flooded with guided funding resulting in a negative image and a business-minded mentality, which has had detrimental effects on their ability to be accepted by their potential constituencies.

Elie Abouaoun, visiting lecturer in human rights of St. Joseph University, director of Middle East Programs, Center for Middle East and Africa, US Institute of Peace, USA; main research field: Human Rights. Email: elie1971@gmail.com. 
Moreover, the legitimacy of the CSS suffers from the sector's spontaneous hostility towards religious values and establishment. Working under the assumption that the only solution is western style secularism, most of the CSS actors fail to recognize that more than two thirds of the current world's population identifies with a religion and that this factor is more ostensible in a region where a belief system emerges as a core source of identity. While clerics use religious language to mobilize followers and widen their base of support, political leaders use religious discourse to garner popular support for specific policy aims or make space for their group that may feel discriminated and/or marginalized. CSS actors do not give enough thought about the linkages that have to be established with and between these two trends and how to relate it to human rights work; therefore, deepening the gap between the CSS and its potential constituency.

Similarly, building a constituency for human rights in the region requires a public endorsement of the human rights values. The element that has yet to become clear is whether the popular paradigms in the Arab region favor human rights in general. There is no question that the success and sustainability of right based interventions are intimately linked to a buy-in from society itself. As such, it is not enough for CSS actors to implement projects or randomly support their communities. They must also engage initiatives aimed at popularizing the universal values of human rights, so that they become the foundation of the social order.

However, most Arab CSS actors have continuously relied on foreign funding because of the absence of local and unconditional funding to human rights initiatives. This has impeded their capacity to drift away from their funders' restrictive agendas. Unfortunately, most of the main funding agencies are yet to be convinced of the importance of investing in long-term endeavors by local actors to trigger a social change in favor of a better endorsement of human rights values by communities. As such, a large portion of foreign funding is still directed to support specific thematic and mostly short-term interventions. The few actors who try to challenge this trend found themselves in financial hardship as soon as they try to resist their funders' agendas.

Alternatively, the post 2011 environment favors established and large civil society groups at the expense of grassroots groups because of a prevailing assumption by large donors that technical capacity refers only to the ability to design and implement a project on time and as per the approved project proposal. In practice, those who are granted most of the resources are the ones able to fill out the forms and have fancy accounting systems, such as urban-based NGOs, often disassociated from the communities around them. However, these actors may not necessarily be the ones who are aware of the needs to be addressed or how to accomplish it in the local context.

While accountability to donors is essential, the value of being accountable to the constituency is almost absent. This widens the gap further with the community and negatively affects the legitimacy and acceptability of CS actors. The weak culture of accountability in the region, even among the CSOs who refrain from imposing accountability towards their constituencies, contributes to the weak legitimacy and acceptability of the sector as a whole.

Beyond the issue of legitimacy lies another obstacle: It is the distorted perception about human rights work. This latter is pictured in general as being anti-governmental by nature. If it is true that the relationship between CSOs and the governments during the last decades is mostly characterized by a deep mistrust and hostility, maintaining an ongoing hostile attitude towards the governments is surely counterproductive. Engaging in cooperative problem solving some human rights issues at least is key to the proper positioning of the CSS and will dismiss the concern that human rights work is anti-governmental. What are still missing is that by taking all human rights work as a package, confrontation with the government is required only on a limited basis. 
Otherwise, many interventions can still be done through cooperation with stakeholders including national and local authorities.

Finally yet importantly, the fact is that national legislations in the region have embraced more human rights principles. Despite that the governments' practices are far from complying with international standards, it remains that the numbers of international treaties and conventions signed and ratified over the last years by Arab governments have increased with all the requirements to the relevant UN relevant bodies.

\section{Way forward}

Only three decades ago, governmental stakeholders strongly questioned the role of CS actors in many fields including human rights. Actually, the role of the latter was perceived as an "invasion" of the "public" sphere by unknown non-governmental actors. Nowadays, this role is more acknowledged than ever before and the public sector cannot claim exclusivity in serving the public good anymore. There are even more actors involved in the struggle for better respect of human rights, such as the corporate sector, academia, and others. This is why it becomes urgent for the CSO in the Arab region to shift their mode of operation to one based on inclusiveness (e.g., envisage working with governments, religious institutions...) and collaborative approaches. Building alliances, even when their scope is thematically or geographically limited, is not optional anymore.

In addition to inclusiveness and collaboration addressing issues such as building a constituency for human rights, strengthening accountability framework of the CSS, effectiveness of CSO, professional public communication, and cultivating local philanthropy for human rights seem to be a priority on the agenda.

Previous experiences show that transitions to democracies are not reversible and no matter how costly they can be, they will lead to a renewed social contract in each of the affected countries. Moreover, despite of the horrors seen in Libya and Syria, this dynamic will spill over to other countries in the midterm. In this context, CS actors will have a vital role to play. Will they qualify for this role? 